\title{
Türkiye'de 0-10 yaș aralığındaki çocukların testis hacimleri ve penis boyu uzunluğu: ölçümler coğrafi bölgeler arasında farklılık gösterir mi?
}

\section{Testicular volume, and penile length of children aged 0-10 years in Turkey: Do measurements vary among geographical regions?}

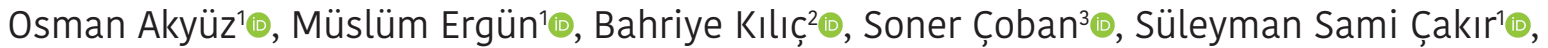 \\ Ahmed Hamdi Tefekli®
}

\section{öz}

AMAC̦: Bu çalışmada 0-10 yaş çocukluk dönemindeki çocukların ortalama penis boyu uzunluğu ve testis hacimlerinin belirlenerek, coğrafi bölgelere göre farklılık gösterip göstermediklerinin araştırılması amaçlandı. GEREC ve YÖNTEMLER: Kurumumuz üroloji polikliniğine 2015 - 2020 yılları arasında sünnet ya da muayene için başvuran, yaşları 7 gün -10 yaș arasında değișen 1156 erkek çocuk çalıșmamıza dahil edildi. Penis dorsumunda pubik kemikten meatusa kadar olan mesafe sert bir cetvelle ölçülerek gergin haldeki penis boyu ölçümü gerçekleștirildi. Testis hacimleri ise Prader orşidometrisi kullanılarak ölçüldü. Çalışmaya dahil olan çocuklar Türkiye'nin coğrafik bölgelerine göre yedi farklı gruba ayrild.

BULGULAR: Çalışmaya dahil edilen hastaların yaş ortalaması $4,35 \pm 2,65$ yıl, penis boyu ortalamas $5,43 \pm 1,11 \mathrm{~cm}$, sağ ve sol testis ortalama hacimleri ise sırasıyla olmak üzere $3,15 \pm 1,20$ ve $3,14 \pm 1,19 \mathrm{~cm}^{3}$ olarak saptandı. Bölgeler arasında penis boy uzunlukları için istatistiksel olarak anlamlı farklılık saptanmadı $(\mathrm{p}=0,195)$. Sağ ve sol testis hacimleri Karadeniz Bölgesi'nde Doğu Anadolu Bölgesi'ne göre ve İç Anadolu Bölgesi için Doğu ve Güneydoğu Anadolu Bölge'lerine göre anlamlı yüksek bulundu ( $p=0,013$ ve $p=0,001)$. Ortalama penis boyu uzunluğu yaş ve boy ile güçlü, ağırlık ile orta derecede güçlü ve vucut kitle indeksi için zayıf pozitif korelasyon gösterdi. Ortalama sağ ve sol testis hacmi ise yaş, boy ve ağılılı ile orta derecede güçlü, vucut kitle indeksi ile zayıf pozitif korelasyon gösterdi.

SONUÇ: Bu çalışma, ülkemizde 0-10 yaş aralı̆̆ındaki çocukların penil uzunluk ve testis hacim ölçümlerinden elde edilen değerleri sunmaktadır. Ortalama penis boyu uzunluğu bölgelere göre farklılık göstermezken, testis hacimleri ise bazı bölgeler için anlamlı farklık göstermektedir. Anahtar Kelimeler: yaş, çocuk, coğrafi bölge, penis, testis

${ }^{7}$ Atlas Üniversitesi, Medicine Hospital, Üroloji Anabilim Dalı, İstanbul, Türkiye ${ }^{2}$ Atlas Üniversitesi, Medicine Hospital, Anesteziyoloji ve Reanimasyon Anabilim Dalı, istanbul, Türkiye

${ }^{3}$ Yüksek Ihtisas Eğitim ve Araştırma Hastanesi, Üroloji Anabilim Dalı, Bursa, Türkiye

Yazışma Adresi/ Correspondence:

Dr. Öğr. Üyesi Osman Akyüz

Hoca Ahmet Yesevi 149, 34000 İstanbul - Türkiye

Tel: $\quad+905327919430$

E-mail: akyuzosman@hotmail.com

Gelis/ Received: $\quad 06.07 .2020$

Kabul/ Accepted: $\quad 09.08 .2020$

\section{ABSTRACT}

OBJECTIVE: In this study, it was aimed to determine average penile length, and testicular volumes of children aged $0-10$ years, and to investigate whether these measurements differ by geographical regions. MATERIAL and METHODS: A total of 1156 boys, aged between 7 days and 10 years, who applied to the Urology outpatient clinic between 2015 and 2020 for circumcision or examination, were included in our study. On the dorsal surface of the stretched penis, the distance from the pubic bone to the meatus was measured with a hard ruler. Testicular volumes were measured using Prader orchidometer. The children participated in the study were divided into 7 different groups according to the geographical regions of Turkey.

RESULTS: The mean age of the patients included in the study was $4.35 \pm 2.65$ years, the average penile length was $5.43 \pm 1.11 \mathrm{~cm}$, and the mean volumes of the right and left testicles were $3.15 \pm 1.20$ and $3.14 \pm 1.19 \mathrm{~cm}^{3}$, respectively. There was no statistically significant difference between the regions for penile lengths $(\mathrm{p}=0.195)$. Right and left testicle volumes were found to be significantly higher in the Black Sea Region than in the Eastern Anatolia Region and in the Eastern and Southeastern Anatolia Regions for the Central Anatolia region ( $\mathrm{p}=0.013$ and $\mathrm{p}=0.001$ ). Average penile length demonstrated strong correlation with age and height, moderately strong corerlation with weight, and weakly positive correlation with body mass index. Mean volumes for right and left testicles demonstrated moderately strong correlation with age, height and weight, and weak correlation with body mass index. CONCLUSION: This study presents penile length and testicular volume measurements of 1156 male children aged $0-10$ years in our country. While average penile length does not differ by region, testicular volumes differ significantly for some regions.

Keywords: age, child, geographic area, penis, testicle

\section{GíRiș}

Penis boyları ve testis boyutlarındaki anormalliklerin erken tanısı, hem varsa altta yatan nedenin ortaya konulaabilmesi açısından hem de psikolojik açıdan önem taşır. Küçük bir penis bazen hipotalamik ya da hipofizer aksta problemin erken dönem göstergesi olabilir. ${ }^{[1]}$ Aynı zamanda mikropenis gibi penil problemler, gelişim sürecinde çocukların psikolojisini olumsuz yönde etkileyebilmektedir. ${ }^{\left[{ }^{[2]}\right.}$ 
Günümüzde üroloji polikliniklerine sık başvuru sebeplerinden bir tanesi de penis boyunun normalden küçük olduğunun düşünülmesidir. $\mathrm{Bu}$ duruma özellikle obez çocuklarda pubik yağ dokusunun fazlalığına bağlı gelişen gömük penis nedeniyle daha sık rastlanılmaktadır. Aileler penisin görünümünden tedirgin olmakta, bazen de çocuklar arkadaşlarının penis görüntüsü ile kıyaslama yapıp kendi penisinin küçük olduğunu düşünmektedir. Ebeveynlere tatmin edici açıklamalar yapılabilmesi için yaşlara göre normal penis boylarının referans değerlerinin bilinmesi gerekmektedir. Penis boyundaki anormallikler, sağlıklı çocuklarda penis boyunun güncel referans değerleri ile karşılaştırılarak belirlenebilir. Ancak ülkemizde sağlıklı çocukların yaşa göre penis ölçüm boyutlarını ortaya koyan ve referans değerler olışturabilecek çalışmaların sayısı sınırlıdır. Çamurdan ve ark., Ankara’da 1040 çocuğu kapsayan çalışmada penil normogram oluşturmuşlar ve $0-5$ yaş arası çocuklar için ülkemizde referans değeri olarak kullanılabileceğini bildirmişlerdir. ${ }^{[3]}$

Kurumumuzun olduğu bölge, ülkemizin her yerinden göç alan, dolayısıyla her bölgeden ailelerin yaşadığ 1 bir yerdir. Literatürde ülkemizde tüm coğrafi bölgeleri kapsayacak şekilde çocukların penis boyu ve testis volumlerini değerlendiren bir çalışmaya rastlayamadık. Aslan ve ark., penis boyu ile ilgili ülkemizin genelini kapsayan bir çalışma yapmış olsalar da, bu çalışmadaki hastalar çocuklarsdan değil, genç erişkin erkeklerden oluşmaktaydı. ${ }^{[4]}$ Çocuklarda yapılan çalışmalar ise lokal olup iller bazında yapılmışıır. Bu çalışmada 0-10 yaş çocukluk döneminde, çocukların ortalama penis boyu ve testis hacimlerinin belirlenmesi amaçlandı. Ek olarak elde edilen verilerin coğrafi bölgelere göre farklılık gösterip göstermedikleri araştırıldı.

\section{GEREÇ VE YÖNTEMLER}

Hastanemizde Aralık 2015 ile Ocak 2020 tarihleri arasında, yaşları 7 gün ile 10 yaş (yaş ortalaması 4,35 $\pm 2,65$ yıl) arasında değişen, sünnet veya muayene için başvuran, toplam 1190 çocuğa ait verileri içeren dosya ve bilgisayar kayıtları retrospektif olarak incelendi. Konjenital penil anomalisi [epispadias (n: 1), hipospadias (n: 14)] olan, prematüre doğum öyküsü olan (n=9), püberte göstergesi açısından genital kıllanması olan $(n=8)$ ve endokrinopatiye bağlı gelişme geriliği öyküsü olan $(\mathrm{n}=2)$ hastalar çalışma dışı bırakıldı. Bunların dışında kalan 1156 hasta çalışmaya dahil edildi. Tablo 1'de çalışmaya alınan hastalar ve çalışmanın özellikleri gösterilmiştir. Çocuklar doğdukları illere göre kaydedildi. Ancak İstanbul'da doğmasına rağmen, babaları yakın zamanda İstanbul'a gelerek yerleşmiş çocuklar için, babaların nüfusa kayıtlı olduğu ve göç ettiği il esas alındı. Kendisini yedi göbek (bildiği bütün ceddini) İstanbul'lu tanıtan ailelerin çocuklarının doğum yeri İstanbul olarak kaydedildi. Ardından hastalar Türkiye'de coğrafi bölgelere göre yedi farklı gruba ayrıldı.

Hastaların gergin haldeki penis boyu ve testis hacimleri aynı ürolog (OA) tarafından oda sıcaklığında ailelelerinin yanında sırtüstü yatar pozisyonda ölçüldü. Gerilmiş penis boyu ölçülürken milimetre işaretli sert bir cetvel kullanıldı. Yağ dokusu bastırıldıktan sonra pubik kemikten, maksimum gerdirilmiş olan penisin dorsali boyunca glans ucuna kadar olan mesafe ölçüldü. Penis uzunluk ölçümü iki kez yapıldı ve ortalama değer kaydedildi. Çocukların testis hacimlerini belirlemek için bimanual palpasyonla testisler ortaya konuldu. Ardından hacimleri 1 ila 25 $\mathrm{cm}^{3}$ arasında değişen bir Prader orşidometrisi kullanılarak ölçüldü (Şekil 1). ${ }^{[5,6]}$ Muayene esnasında hipospadias, inmemiş testis gibi konjenital anomalisi saptanmış olan hastaların kayıtları ayrıca tutuldu. Yirmi dört aya kadar olan bebeklerin boy ölçümü portable bir infantometre, ağırlıkları ise dijital bebek terazisi ile ölçüldü. Daha büyük çocukların boyları ve ağırlıkları mekanik boy ölçerli dijital baskül ile ölçüldü.

İstatistiksel analiz için SPSS programı (SPSS version 20.0; IBM, NY, USA) kullanıldı. Sonuçlar tanımlayıcı istatistikler (sayısal veriler için ortalama, standart sapma) ve Pearson korelasyon analizi kullanılarak değerlendirildi. Normal dağılım gösteren sayısal değişkenler için One-Way Anova testi, normal dağılım göstermeyenler için Kruskal-Wallis sıralamalı tek yönlü varyans analizi kullanıldı. Bu çalışma Helsinki Bildirgesi'ne uygun olarak yapılmıştır.

\section{BULGULAR}

Çalışmaya dahil edilen hastaların ortalama yaşı 4,35 $\pm 2,65$ yıl olarak belirlendi. Hastaların karakteristik özellikleri Tablo 1'de tanımlanmıştır. Ortalama penis boyu 5,43 $\pm 1,11$

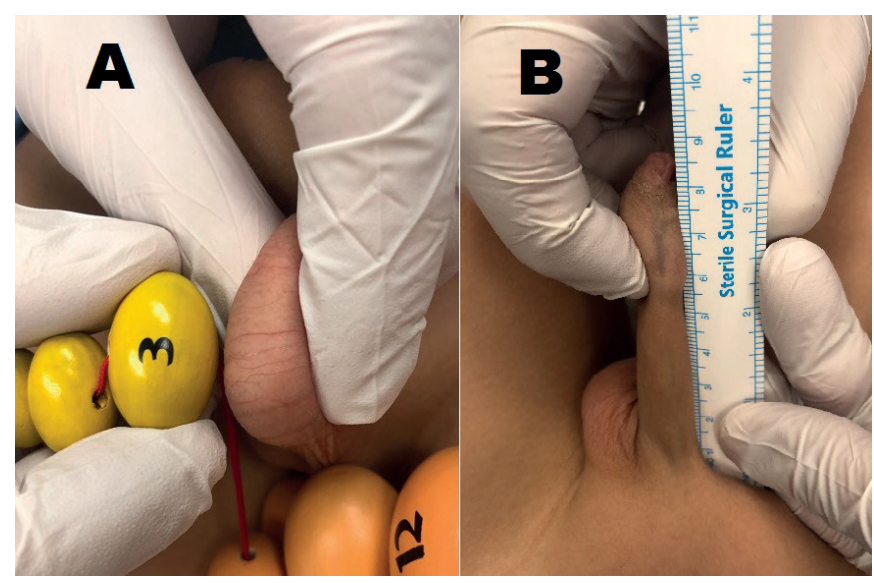

Şekil 1A: Prader orşidometrisi ile testis hacmi ölçümü, 1B: Sert bir cetvelle yapılan penis boyu ölçümü 
cm olarak bulunmuş olup bölgeler arasında istatistiksel olarak anlamlı farklılık saptanmadı $(\mathrm{P}=0,195)$. Çalışmaya alınan hastaların ortalama testis hacimleri sağ ve sol testis için sirasıly $3,15 \pm 1,20 \mathrm{~cm}^{3}$ ve $3,14 \pm 1,19 \mathrm{~cm}^{3}$ olarak saptand ve ülke geneli için anlamlı farklılık göstermedi $(\mathrm{p}=0,512)$. Ancak bölgelere göre değerlendirme yapıldı̆̆ında sağ ve sol testis hacimleri Karadeniz Bölgesi'nde, Doğu Anadolu Bölgesi'ne göre anlamlı yüksek bulundu ( $\mathrm{p}=0,013)$. Yine sağ ve sol testis hacimleri İç Anadolu Bölgesi için, Doğu ve Güneydoğu Anadolu Bölge’lerine göre anlamlı yüksek bulundu ( $\mathrm{p}=0,001)$. Coğrafik bölgelere göre erkeklerin testis volüm ve penis boyu uzunluklarının ortalaması Tablo 2'de gösterilmiştir.

\section{Tablo 1. Çalışmanın karakteristikleri}

\begin{tabular}{lc}
\hline Hasta sayısı $(\mathrm{n})$ & 1156 \\
Yaşortalaması & $4,35 \pm 2,65$ \\
Boy ortalaması & $103,37 \pm 24,07$ \\
Kilo ortalaması & $27,07 \pm 18,32$ \\
Vücut kitle indeksi ortalaması & $16,06 \pm 2,63$ \\
Penis boyu ortalaması $\left(\mathrm{cm}^{3}\right.$ & $5,43 \pm 1,11$ \\
Ortalama testis hacmi $\left(\mathrm{cm}^{3}\right)$ & $3,15 \pm 1,20$ \\
Sağ & $3,14 \pm 1,19$ \\
Sol & \\
\hline $\mathrm{n}$, hasta sayısı; cm, santimetre. &
\end{tabular}

Penis boy yaş aralığı - bölge ilişkisi incelendiğinde yaş gruplarında bölgeler arasında anlamlı farklılık saptanmadı (Tablo 3,4). Sağ ve sol testis hacmi ise bazı yaş grupları için bölgeler arasında anlamlı farklılık gösterdi. Testis hacimleri arasında $0-0,5$ yaş ve $0,5-1$ yaş gruplarında farklılık saptanmadı. Sağ testis hacmi 1-2 yaş aralığında İç Anadolu Bölgesi için Doğu Anadolu'ya göre anlamlı olarak yüksek bulundu ( $\mathrm{p}=0,013)$. Ancak bu grupta sol testis için anlamlı farklılık saptanmadi.

Sağ testis hacmi 2-3 yaş aralığında Ege Bölgesi için, Doğu ve Güneydoğu Anadolu Bölgesi'ne göre anlamlı yüksek saptandı $(p=0,02$ ve $p=0,046)$. Yine bu yaş aralığında Karadeniz Bölgesi için sağ testis hacim ölçümleri, Doğu Anadolu Bölgesi'ne göre yüksek bulundu $(\mathrm{p}=0,025)$. Aynı yaş aralığında sol testis hacimleri incelendiğinde Marmara, Akdeniz ve Karadeniz Bölgesi'nde, Doğu Anadolu Bölgesi'ne göre anlamlı yüksek bulundu. Yine sol testis hacmi Ege Bölgesi için Doğu ve Güneydoğu Anadolu Bölgesi'ne göre anlamlı yüksek sap$\operatorname{tand}_{1}(\mathrm{p}=0,001)$.

Üç-dört yaş aralığında sağ testis hacmi, Marmara ve Karadeniz Bölgesi'nde Doğu Anadolu Bölgesi'ne göre anlamlı olarak yüksek bulundu ( $\mathrm{p}=0,041$ ve $\mathrm{p}=0,002)$.

Tablo 2. Coğrafik bölgelere göre çocukların testis hacmi/penis boyu uzunluklarının ortalama ve standart sapması

\begin{tabular}{lccccc}
\hline Coğrafi bölge & $n$ & Yaş (yıl) & Sağ testis $\left(\mathrm{cm}^{3}\right)$ & Sol testis $\left(\mathrm{cm}^{3}\right)$ & Penis boy $\left(\mathrm{cm}^{3}\right)$ \\
\hline Marmara & 159 & $4,19 \pm 2,41$ & $3,10 \pm 0,96$ & $3,10 \pm 0,97$ & $5,50 \pm 1,05$ \\
Ege & 105 & $4,38 \pm 2,90$ & $3,17 \pm 1,26$ & $3,15 \pm 1,27$ & $5,46 \pm 1,25$ \\
Akdeniz & 102 & $4,51 \pm 2,75$ & $3,26 \pm 1,11$ & $3,25 \pm 1,08$ & $5,25 \pm 0,97$ \\
Karadeniz & 290 & $4,33 \pm 2,64$ & $3,27 \pm 1,30$ & $3,26 \pm 1,31$ & $5,40 \pm 1,14$ \\
Doğu Anadolu & 227 & $4,52 \pm 2,75$ & $2,85 \pm 1,13$ & $2,89 \pm 1,11$ & $5,56 \pm 1,08$ \\
Güneydoğu Anadolu & 152 & $4,08 \pm 2,60$ & $2,94 \pm 1,09$ & $2,92 \pm 1,10$ & $5,32 \pm 1,13$ \\
i̇c Anadolu & 121 & $4,50 \pm 2,59$ & $3,48 \pm 1,32$ & $3,52 \pm 1,29$ & $5,40 \pm 1,08$ \\
\hline
\end{tabular}

$\mathrm{n}$, hasta sayısl; $\mathrm{cm}$, santimetre.

Tablo 3. Yaş aralıklarına göre ülkemiz genelinde çocukların penis boyu $(\mathrm{cm}) /$ testis hacimleri ortalama $\left(\mathrm{cm}^{3}\right)$ ve standart sapması

\begin{tabular}{lcccc}
\hline Yaş (yıl) & $n$ & Penis boyu $(\mathrm{cm})$ & Sağ testis hacmi $\left(\mathrm{cm}^{3}\right)$ & Sol testis hacmi $\left(\mathrm{cm}^{3}\right)$ \\
\hline $\mathbf{0 - 0 , 5}$ & 102 & $4,24 \pm 0,67$ & $1,97 \pm 0,65$ & $1,98 \pm 0,68$ \\
$\mathbf{0 , 5 - 1}$ & 28 & $4,63 \pm 0,57$ & $2,16 \pm 0,67$ & $2,18 \pm 0,73$ \\
$\mathbf{1 - 2}$ & 110 & $4,60 \pm 0,73$ & $2,50 \pm 0,68$ & $2,55 \pm 0,77$ \\
$\mathbf{2 - 3}$ & 123 & $4,93 \pm 0,73$ & $2,57 \pm 0,74$ & $2,73 \pm 0,73$ \\
$\mathbf{3 - 4}$ & 89 & $5,10 \pm 0,87$ & $2,85 \pm 0,76$ & $2,82 \pm 0,74$ \\
$\mathbf{4 - 5}$ & 127 & $5,26 \pm 0,72$ & $3,24 \pm 0,91$ & $3,20 \pm 0,92$ \\
$\mathbf{5 - 6}$ & 156 & $5,66 \pm 0,95$ & $3,32 \pm 0,97$ & $3,26 \pm 0,99$ \\
$\mathbf{6 - 7}$ & 135 & $5,98 \pm 0,88$ & $3,47 \pm 1,02$ & $3,47 \pm 1,05$ \\
$\mathbf{7 - 8}$ & 135 & $6,19 \pm 1,00$ & $3,56 \pm 1,32$ & $3,56 \pm 1,33$ \\
$\mathbf{8 - 9}$ & 79 & $6,38 \pm 1,10$ & $4,05 \pm 1,42$ & $4,09 \pm 1,24$ \\
$\mathbf{9 - 1 0}$ & 62 & $6,48 \pm 1,14$ & $4,58 \pm 1,58$ & $4,63 \pm 1,52$ \\
\hline
\end{tabular}

$\mathrm{n}$, hasta sayısi; $\mathrm{cm}$, santimetre. 
Sol testis hacmi ise sadece Karadeniz Bölgesi'nde, yine Doğu Anadolu Bölgesine göre anlamlı yüksek bulundu $(\mathrm{p}=0,08)$.

Dört-beş yaş aralığında sağ testis hacmi, Karadeniz Bölgesi'nde Ege, Doğu Anadolu ve Güneydoğu Anadolu Bölgesi'ne göre anlamlı olarak yüksek bulundu ( $\mathrm{p}=0,008$, $\mathrm{p}=0,006, \mathrm{p}=0,030)$. Aynı grupta sol testis hacmi ise yine Karadeniz Bölgesi'nde, Ege ve Doğu Anadolu Bölgesi'ne göre anlamlı yüksek bulundu ( $\mathrm{p}=0,031, \mathrm{p}=0,014)$.

Testis hacimleri 5-6, 6-7 ve 7-8 ve 9-10 yaş aralığında bölgeler arasında anlamlı farklılık göstermedi. Sağ ve sol testis volümü 8-9 yaş aralığında, İç Anadolu Bölgesi için Karadeniz Bölgesi'ne göre anlamlı fazla saptandı (Tablo 5,6) $(\mathrm{p}=0,033, \mathrm{p}=0,020)$.

Ortalama penis boyu uzunluğu, yaş ve boy ile güçlü pozitif korelasyon $(r=0,612, r=0,621)$, ağırlık ile orta derecede güçlü korelasyon $(r=0,571)$ gösterdi. Ancak vücut kitle indeksi ile olan korelasyon zayıftı $(\mathrm{r}=0,047, \mathrm{p}<0,001)$. Ortalama sağ ve sol testis hacmi yaş, boy ve ağırlık ile orta derecede güçlü pozitif, vucut kitle indeksi ile zayıf pozitif korelasyon gösterdi (sağ testis için sırasıyla $\mathrm{r}=0,527$, $\mathrm{r}=0,509, \mathrm{r}=0,486, \mathrm{r}=0,047$; sol testis hacmi için sırasıyla $\mathrm{r}=0,533, \mathrm{r}=0,511, \mathrm{r}=0,495, \mathrm{r}=0,082, \mathrm{p}<0,001)$.

Tablo 4. Yaş aralıklarına göre bölgelerde saptanan penis boyu ortalaması (cm) ve standart sapması

\begin{tabular}{|c|c|c|c|c|c|c|c|c|c|}
\hline Yaş & $n$ & $M$ & $E$ & $A$ & $K$ & $i A$ & $D A$ & $G D A$ & $P$ \\
\hline $0-0,5$ & 102 & $4,5 \pm 0,4$ & $4,2 \pm 0,7$ & $4,1 \pm 0,7$ & $4,2 \pm 0,8$ & $4,1 \pm 0,7$ & $4,3 \pm 0,6$ & $4,0 \pm 0,6$ & 0,581 \\
\hline $0,5-1$ & 38 & $4,5 \pm 0,7$ & $4,6 \pm 0,8$ & $4,6 \pm 0,4$ & $4,6 \pm 0,4$ & $5,0 \pm 0,8$ & $4,6 \pm 0,4$ & $4,1 \pm 0,7$ & 0,838 \\
\hline $1-2$ & 110 & $4,3 \pm 0,4$ & $4,3 \pm 0,4$ & $4,8 \pm 1,3$ & $4,4 \pm 0,1$ & $4,3 \pm 0,2$ & $4,9 \pm 0,5$ & $4,6 \pm 0,5$ & 0,122 \\
\hline $2-3$ & 123 & $5,2 \pm 0,5$ & $5,2 \pm 0,2$ & $4,5 \pm 0,5$ & $4,9 \pm 0,0$ & $4,6 \pm 0,5$ & $5,1 \pm 0,7$ & $4,7 \pm 0,2$ & 0,051 \\
\hline $3-4$ & 89 & $5,2 \pm 0,7$ & $5,2 \pm 0,6$ & $5,1 \pm 0,6$ & $5,2 \pm 0,2$ & $4,5 \pm 0,4$ & $5,3 \pm 0,3$ & $5,1 \pm 0,8$ & 0,543 \\
\hline $4-5$ & 127 & $5,4 \pm 0,8$ & $5,1 \pm 0,8$ & $5,3 \pm 0,7$ & $5,2 \pm 0,8$ & $5,0 \pm 0,6$ & $5,2 \pm 0,6$ & $5,3 \pm 0,6$ & 0,733 \\
\hline $5-6$ & 156 & $5,7 \pm 0,8$ & $5,2 \pm 0,9$ & $5,2 \pm 0,6$ & $5,6 \pm 0,9$ & $5,8 \pm 1,0$ & $5,9 \pm 0,9$ & $5,5 \pm 1,0$ & 0,382 \\
\hline $6-7$ & 135 & $6,3 \pm 1,0$ & $5,5 \pm 1,0$ & $5,8 \pm 0,8$ & $5,6 \pm 0,8$ & $5,8 \pm 0,6$ & $6,1 \pm 0,7$ & $6,1 \pm 1,0$ & 0,638 \\
\hline $7-8$ & 135 & $6,0 \pm 0,7$ & $6,5 \pm 0,7$ & $5,7 \pm 0,7$ & $6,4 \pm 0,9$ & $6,0 \pm 0,9$ & $6,1 \pm 1,2$ & $5,8 \pm 1,1$ & 0,129 \\
\hline $8-9$ & 79 & $6,1 \pm 1,2$ & $6,7 \pm 1,5$ & $6,1 \pm 1,4$ & $6,2 \pm 0,8$ & $6,4 \pm 0,9$ & $6,6 \pm 1,0$ & $6,0 \pm 0,9$ & 0,746 \\
\hline 9-10 & 62 & $7,5 \pm 0,5$ & $6,4 \pm 1,4$ & $5,8 \pm 0,5$ & $6,9 \pm 1,6$ & $6,1 \pm 0,7$ & $6,1 \pm 0,7$ & $6,9 \pm 0,8$ & 0,073 \\
\hline
\end{tabular}

M, Marmara; E, Ege; A, Akdeniz; K, Karadeniz; IA, İç Anadolu; DA, Doğu Anadolu; GDA, Güneydoğu Anadolu; n, Hasta sayısı *istatistiksel olarak anlamlı.

Tablo 5. Yaş aralıklarına göre bölgelerde saptanan sağ testis hacmi ortalaması $\left(\mathrm{cm}^{3}\right)$ ve standart sapması

\begin{tabular}{|c|c|c|c|c|c|c|c|c|c|}
\hline Yaş & $n$ & $M$ & $E$ & $A$ & $K$ & $i A$ & $D A$ & $G D A$ & $P$ \\
\hline $0-0,5$ & 102 & $2,1 \pm 0,4$ & $1,8 \pm 0,7$ & $2,2 \pm 0,4$ & $2,0 \pm 0,8$ & $2,1 \pm 0,9$ & $1,7 \pm 0,4$ & $1,9 \pm 0,7$ & 0,354 \\
\hline $0,5-1$ & 38 & $2,5 \pm 0,7$ & $2,3 \pm 0,5$ & $2,2 \pm 0,8$ & $2,0 \pm 0,8$ & $1,7 \pm 0,9$ & $2,3 \pm 0,5$ & $2,3 \pm 0,5$ & 0,764 \\
\hline $1-2$ & 110 & $2,5 \pm 0,2$ & $2,7 \pm 0,7$ & $2,8 \pm 0,4$ & $2,5 \pm 0,4$ & $3,1 \pm 0,2$ & $2,2 \pm 0,1$ & $2,2 \pm 0,4$ & $0,013 *$ \\
\hline $2-3$ & 123 & $2,8 \pm 0,4$ & $3,3 \pm 0,8$ & $2,8 \pm 0,1$ & $2,9 \pm 0,6$ & $3,2 \pm 0,2$ & $2,2 \pm 0,4$ & $2,5 \pm 0,7$ & $0,001 *$ \\
\hline $3-4$ & 89 & $2,8 \pm 0,7$ & $2,8 \pm 0,3$ & $2,9 \pm 0,5$ & $3,2 \pm 0,3$ & $3,2 \pm 0,6$ & $2,1 \pm 0,7$ & $2,7 \pm 0,6$ & $0,008 *$ \\
\hline $4-5$ & 127 & $3,0 \pm 0,9$ & $2,8 \pm 0,3$ & $3,0 \pm 0,8$ & $3,6 \pm 0,9$ & $3,7 \pm 1,1$ & $2,8 \pm 0,6$ & $2,9 \pm 0,5$ & $0,003 *$ \\
\hline $5-6$ & 156 & $3,3 \pm 0,8$ & $3,1 \pm 0,8$ & $3,6 \pm 0,7$ & $3,3 \pm 1,1$ & $3,6 \pm 1,1$ & $3,0 \pm 0,9$ & $3,0 \pm 0,5$ & 0,259 \\
\hline $6-7$ & 135 & $3,7 \pm 1,0$ & $3,0 \pm 0,7$ & $3,4 \pm 1,1$ & $3,6 \pm 0,8$ & $3,2 \pm 0,9$ & $3,4 \pm 1,2$ & $3,4 \pm 0,9$ & 0,621 \\
\hline $7-8$ & 135 & $3,2 \pm 0,7$ & $3,7 \pm 1,4$ & $4,3 \pm 1,0$ & $3,9 \pm 1,7$ & $3,6 \pm 1,4$ & $3,1 \pm 0,8$ & $3,0 \pm 0,9$ & 0,081 \\
\hline 8-9 & 79 & $4,3 \pm 0,9$ & $4,2 \pm 1,5$ & $4,0 \pm 1,4$ & $3,2 \pm 1,3$ & $5,4 \pm 1,4$ & $3,7 \pm 1,2$ & $4,5 \pm 0,9$ & $0,017^{*}$ \\
\hline 9-10 & 62 & $4,0 \pm 0,9$ & $5,0 \pm 1,5$ & $4,0 \pm 1,4$ & $4,9 \pm 1,3$ & $4,6 \pm 1,4$ & $4,4 \pm 1,2$ & $4,7 \pm 0,9$ & 0,912 \\
\hline
\end{tabular}

M, Marmara; E, Ege; A, Akdeniz; K, Karadeniz; IA, İç Anadolu; DA, Doğu Anadolu; GDA, Güneydoğu Anadolu; n, Hasta sayıSı

*Bölgeler arasında istatistiksel olarak anlamlı farklılık. 
Tablo 6. Yaş aralıklarına göre bölgelerde saptanan sol testis hacmi ortalaması $\left(\mathrm{cm}^{3}\right)$ ve standart sapması

\begin{tabular}{|c|c|c|c|c|c|c|c|c|c|}
\hline Yaş & $n$ & $M$ & $E$ & $A$ & $K$ & $i A$ & $D A$ & $G D A$ & $P$ \\
\hline $0-0,5$ & 102 & $2,1 \pm 0,5$ & $1,7 \pm 0,7$ & $2,3 \pm 0,5$ & $1,9 \pm 0,8$ & $2,2 \pm 1,0$ & $1,8 \pm 0,3$ & $1,9 \pm 0,7$ & 0,838 \\
\hline $0,5-1$ & 38 & $2,5 \pm 0,7$ & $2,3 \pm 0,5$ & $2,2 \pm 1,0$ & $2,0 \pm 0,9$ & $2,1 \pm 0,8$ & $2,3 \pm 0,4$ & $2,0 \pm 0,5$ & 0,974 \\
\hline $1-2$ & 110 & $2,5 \pm 0,2$ & $2,7 \pm 0,2$ & $2,8 \pm 0,4$ & $2,5 \pm 0,1$ & $3,2 \pm 0,2$ & $2,3 \pm 1,0$ & $2,2 \pm 1,0$ & 0,053 \\
\hline $2-3$ & 123 & $2,8 \pm 0,5$ & $3,3 \pm 0,7$ & $2,8 \pm 0,8$ & $2,8 \pm 0,1$ & $3,2 \pm 0,7$ & $2,2 \pm 0,6$ & $2,5 \pm 0,4$ & $0,001^{*}$ \\
\hline $3-4$ & 89 & $2,7 \pm 0,7$ & $2,6 \pm 0,3$ & $2,8 \pm 0,5$ & $3,2 \pm 0,2$ & $3,2 \pm 0,5$ & $2,2 \pm 0,4$ & $2,6 \pm 0,7$ & $0,014 *$ \\
\hline $4-5$ & 127 & $3,0 \pm 0,9$ & $2,8 \pm 0,3$ & $3,0 \pm 0,8$ & $3,5 \pm 1,0$ & $3,7 \pm 1,0$ & $2,7 \pm 0,6$ & $2,9 \pm 0,5$ & $0,004 *$ \\
\hline $5-6$ & 156 & $3,2 \pm 0,8$ & $3,0 \pm 0,8$ & $3,6 \pm 0,7$ & $3,2 \pm 1,2$ & $3,6 \pm 1,1$ & $2,9 \pm 0,8$ & $3,0 \pm 0,5$ & 0,178 \\
\hline $6-7$ & 135 & $3,6 \pm 1,0$ & $3,1 \pm 0,6$ & $3,4 \pm 1,1$ & $3,6 \pm 0,8$ & $3,3 \pm 1,0$ & $3,4 \pm 1,1$ & $3,4 \pm 0,9$ & 0,636 \\
\hline $7-8$ & 135 & $3,3 \pm 0,7$ & $3,7 \pm 1,4$ & $4,3 \pm 1,0$ & $3,9 \pm 1,7$ & $3,6 \pm 1,4$ & $3,1 \pm 0,8$ & $3,0 \pm 1,0$ & 0,070 \\
\hline $8-9$ & 79 & $4,3 \pm 0,9$ & $4,2 \pm 1,5$ & $3,8 \pm 1,3$ & $3,5 \pm 0,8$ & $5,3 \pm 1,1$ & $3,7 \pm 1,2$ & $4,5 \pm 0,9$ & $0,015^{*}$ \\
\hline $9-10$ & 62 & $4,3 \pm 1,5$ & $5,0 \pm 2,0$ & $4,2 \pm 1,2$ & $4,9 \pm 1,5$ & $4,8 \pm 1,4$ & $4,3 \pm 1,2$ & $4,7 \pm 0,9$ & 0,914 \\
\hline
\end{tabular}

M, Marmara; E, Ege; A, Akdeniz; K, Karadeniz; IA, İç Anadolu; DA, Doğu Anadolu; GDA, Güneydoğu Anadolu; n, Hasta sayıSı

*istatistiksel olarak anlamlı.

\section{TARTIȘMA}

Penis boyu ve testis hacimlerinin ölçümü prepübertal dönemde erkek çocukların sağlıklı gelişiminin değerlendirilmesinde önemlidir. Ölçümlerde saptanan anormallikler ciddi endokrinopatisi olan veya kromozom bozukluklarına sahip çocukların belirlenmesinde önemli rol oynayabilir. [7] Günümüzde çoğunlukla ebeveynler daha az oranda da çocuğun kendisi penis boyunun kısa olması veya testislerin ele gelmemesi şikayeti ile üroloji polikliniklerine başvurmaktadırlar. Ancak başvuran hastaların pek çoğunda obesiteye bağlı suprapubik bölgedeki yağ dokusuna gömülü penis saptanır. Daha önce yapilan çalışmalarda bu endişe ile başvuran hastalarda penis boyunun sıklıkla normal değerler içinde olduğu bildirilmiştir. ${ }^{[8]}$ Penis boyutundaki anormalliklerin belirlenebilmesi için penis boyutunun doğru ölçümü ve o topluma göre penis boyunun güncel referans değerlerinin bilinmesi önemlidir. Zira toplumlar arsındaki etnik farklılıklar çocukların ağıllık, boy ve penis uzunluğunda farklılıklara yol açabilir. Nitekim farklı popülasyonlarda yenidoğan döneminde penil uzunluk üzerinde yapılan çalışmalar, 2,86 ile 3,75 cm arasında değişen farklı normal değerler ortaya koymuştur. ${ }^{[9]}$ Penis uzunluğu doğumdan sonraki ilk beş yılda hızlı bir şekilde artmasına rağmen, beş yaşından sonra püberte yaşına kadar olan dönemde aynı hızda artmadığı bildirilmiştir. Bu nedenle beş yaşa kadar olan dönemde penil uzunluk ölçülmesinin ve çocuğun yaşına göre o toplumdaki normal değerlerle karşılaştırılmasının önemli olduğu bildirilmiştir. ${ }^{[3]}$

Penis uzunluğunu ölçmek için kullanılabilecek en iyi tekniğin ne olduğu konusu tartışmalı olup, penis boyunu ölçmek için bazı çalışmalarda pubopenil cilt bileşkesinden glans penis ucuna kadar ölçülen uzunluk kullanırken, bazı çalışmalarda da pubik kemikten glans penis ucuna kadar olan mesafe kullanılmıştır. ${ }^{[10]}$ Bir diğer tartışma konusu da bu iki yöntemden hangisi kullanılırsa kullanılsın ölçüm esnasında penisin sarkık mı, gergin mi ya da erekte vaziyette mi olması gerektiğidir. Penis uzunluğu ile ilgili bilinen ilk çalışma, Loeb tarafından penis sarkık durumda iken yapılan çalışmadır. ${ }^{[11]}$ Schonfeld ve Beebe ise tam olarak gergin durumda ölçülen penis boyu uzunluğunun, ereksiyon halindeki penisin uzunluğu ile hemen hemen aynı olduğunu belirtmişler ve bu şekilde ölçüm yapılmasını önermişlerdir. ${ }^{[12]}$ Penis boyu ölçülürken gerdirme sırasında penise uygulanması gereken kuvvetin miktarı da önemli olup, özellikle farklı gözlemciler tarafından yapılan ölçümler arasında farklılıklar olabileceği de bildirilmiştir. ${ }^{[13]}$ Çalışmamızda penis boyu ölçümleri penis gergin vaziyette yapılmış olup, gözlemciye bağlı ortaya çıkabilecek farklılıkları önlemek amacıyla ölçümler aynı kişi tarafından yapılmıştır.

Bu çalışmada penis boy uzunluğu bölgeler arasında anlamlı farklılık göstermedi. Çocuklarda bölgelere göre penis boyunu araştıran bir çalışma olmadığı için karşılaştırma yapılamadı. Ancak yaş gruplarına göre değerlendirdiğimizde ise, $0-0,5$ ve $0,5-1$ yaş döneminde saptadığımız penis boyu ortalaması sırasiyla 4,24 ve 4,65 cm olup, bu yaş grubu ile ülkemizde yapılmış tek geniş vaka sayılı çalışma olan Çamurdan ve ark.'nın saptadığı değerlerden (sırasıyla 3,80 ve $4,26 \mathrm{~cm}$ ) daha uzun bulundu. Diğer yaş gruplarına bakıldığında ise bizim çalışmamızdaki penis boyu bir miktar altında olsa da Çamurdan ve ark.'nın yaptığı çalışmayla benzer bulundu. Ancak bu çalışmada yer alan hastalar beş yaş ile sınırlıydı. Yine ülkemizde 514 
yenidoğanın penis uzunluğunun ölçüldüğü bir başka çalışmada ise ortalama penis boyu 3,00 cm olarak mevcut çalışmalardan oldukça kısa ölçülmüştür. ${ }^{[14]}$ Varol ve ark. ise Samsun ilinde 6-10 yaş arası çocukların penis boyu ölçümü ile elde ettikleri ortalama değerler yine bizim çalışmamız ile benzerdi. ${ }^{[15]}$ Yıldııım ve ark.'nın aynı yaş grupları için Siirt ilinde yaptıkları çalışmada elde ettikleri penis boyu değerleri ise bizim çalışmamızda saptadıklarımızdan belirgin şekilde kısaydı. Ancak bu çalışmadaki denek sayısının düşük olması (260) bu farklılı̆̆ yabilir. ${ }^{[16]}$ Çalışmamızda penis boyu uzunluğu yaş ve boy ile güçlü, ağırlık ile orta derecede güçlü pozitif korelasyon gösterdi. Bu durum önceki çalışmalarla uyumluydu. Ancak vücut kitle indeksi bizim çalışmamızda, Çamurdan ve ark.'nın yaptığı çalışmanın aksine pozitif yönde zayıf korelasyon gösterdi.

Testis hacim ölçümü için de farklı yöntemler kullanılabilir. Bunlardan biri ultrasonografi ile ölçüm yapılmasıdır. Daha pratik olarak ise her ne kadar subjektif olup uygulayan kişiye göre sonuçlar farklılık gösterse de, kumpas veya değişik tipteki orşidometrelerle ölçüm yapılabilir. [15] Prader tarafından geliştirilen ve $1-25 \mathrm{ml}$ arası hacme sahip testis şekli verilmiş kalıplardan oluşan orşidometre, testis hacmi ölçümünde sıkça kullanılmaktadır. [5] Biz de çalışmamızda Prader orşidometresi kullanarak testis hacimlerini ölçtük. Çalışmamızda belirli bölgeler ve yaş aralığı için testis hacimleri arasında farklılıklar saptadık. Karadeniz ve İç Anadolu Bölgesi için, Doğu ve Güneydoğu Anadolu Bölgesi'ne göre farklılık saptamakla birlikte bu farklılığı açıklayacak net bir öngörümüz bulunmamaktadır. Ölçücüden kaynaklı farklılıkları ortadan kaldırmak için ölçümler aynı kişi tarafından yapıldı. İklim farklılıkları, etnik farklılıklar rol oynamış olabilir. Daha önceki çalışmalarda özellikle penis boyunun etnisiteden etkilenebileceği ve populasyonlar arasında farklılık olduğu bildirilmiştir. ${ }^{[3,9]}$ Ancak yakın zamanda ailesi İstanbul'a göç etmiş ve babasının doğum yerine göre sınıflandırılmış çocuklar için etnik farklılık önemli olsa da, İstanbul'da yaşadıkları için iklimsel farklılıklar geçerli değildi. Bu da çalışmamızı kısıtlayan önemli bir faktördü.

\section{SONUÇ}

Bu çalışma, 0-10 yaş arası Türk erkek çocuklarının penil uzunluk ve testis hacim ölçümlerinden elde edilen değerleri sunmaktadır. Penis boyu uzunluğu coğrafi bölgeler arasında farklılık göstermezken, testis hacimleri belli bölgeler için bazı yaş aralıklarında farklılıklar göstermektedir. Daha geniş spektrumlu, çok merkezli ileri epidemiyolojik çalışmalar yapılarak penis boyu ve testis hacmi ile ilgili ülkemiz geneli için nomogramların çıkartılması faydalı olacaktır.
Etik Kurul Onayı

Çalışmanın tüm aşamalarında Helsinki Bildirgesi ilkeleri takip edildi.

Hakem Değerlendirmesi

Dış bağımsız.

\section{Çıkar Çatışması}

Yazarlar çıkar ilişkisi olmadığını beyan etmişlerdir.

Finansal Destek

Herhangi bir mali destek alınmamıştır.

Ethics Committee Approval

The Helsinki Declaration principles were followed at all stages of the study.

Peer-review

Externally peer-reviewed.

Conflict of Interest

No conflict of interest was declared by the authors.

Financial Disclosure

No financial support has been received.

\section{KAYNAKLAR}

1. Tuladhar R, Davis PG, Batch J, Doyle LW. Establishment of a normal range of penile length in preterm infants. J Paediatr Child Health 1998;34:471-3. [CrossRef]

2. Reilly JM, Woodhouse CR. Small penis and the male sexual role. J Urol 1989;142:569-71. [CrossRef]

3. Çamurdan AD, Öz MÖ, İlhan MN, Çamurdan OM, Şahin F, Beyazova U. Current stretched penile length: cross-sectional study of 1040 healthy Turkish children aged 0 to 5 years. Urology 2007;70:572-5. [CrossRef]

4. Aslan Y, Atan A, Aydın Ö, Nalçacıoğlu V, Tuncel A, Kadıoğlu A. Türkiye’de sağlıklı genç erkeklerde coğrafik bölgelere göre penis boyu: 1.132 vakanın ölçüm bulguları. Turk J Urol 2010;36:43-8. https:// turkishjournalofurology.com/content/files/sayilar/2/buyuk/43-481.pdf

5. Prader A. Testicular size: assessment and clinical importance. Triangle 1966;7:240-3. https://pubmed.ncbi.nlm.nih.gov/5920758/

6. Ryu DS, Cho WY, Chung JM, Kang DI, Lee SD, Park S. Comparison of penile length at 6-24 months between children with unilateral cryptorchidism and a healthy normal cohort. Investig Clin Urol 2018;59:55-60. [CrossRef]

7. Lee PA, Danish RK, Mazur T, Migeon CJ. Micropenis III. Primary hypogonadism, partial androgen insensitivity syndrome, and idiopathic disorders. Johns Hopkins Med J 1980;147:175-81. https://pubmed.ncbi.nlm.nih.gov/7441936/

8. Wylie KR, Eardley I. Penile size and the 'small penis syndrome'. BJU Int 2007;99:1449-55. [CrossRef]

9. Cheng PK, Chanoine JP. Should the definition of micropenis vary according to ethnicity? Horm Res 2001;55:278-81. [CrossRef]

10. Habous M, Muir G, Soliman T, Farag M, Williamson B, Binsaleh S, et al. Outcomes of variation in technique and variation in accuracy of measurement in penile length measurement. Int J Impot Res 2018;30:21-6. [CrossRef]

11. Dillon BE, Chama NB, Honig SC. Penile size and penile enlargement surgery: a review. Int J Impot Res 2008;20:519-29. [CrossRef]

12. Schonfeld WA, Beebe G. Normal Growth and Variation in the Male Genitalia from Birth to Maturity. J Urol 1942;48:759-77. [CrossRef]

13. Chen J, Gefen A, Greenstein A, Matzkin H, Elad D. Predicting penile size during erection. Int J Impot Res 2000;12:328-33. [CrossRef]

14. Kutlu AO. Normative Data for Penile Length in Turkish Newborns. J Clin Res Ped Endo 2010;2:107-10. [CrossRef]

15. Varol S, Özden E, Bostancı Y, Yakupoğlu YK, Yalman C, Sarıkaya Ş. Samsun ilinde ilköğretim çağı erkek çocuklarda testis ve penis boyutları ve diş genital organ anomali oranları. Turk Arch Ped 2011;46:159-63. [CrossRef]

16. Yıldırım ME, Yanaral F, Akçin S. Siirt ilinde sünnet yapılan çocuklarda genital anomali oranları, penis boyu ve testis hacimleri. New J Urol 2013;8:6-9. https://dergipark.org.tr/en/download/ article-file/ 1017727 